\title{
BMJ Open Organic or organised: an interaction analysis to identify how interactional practices influence participation in group decision meetings for residency selection
}

\author{
Lokke Gennissen, ${ }^{1}$ Anne de la Croix, ${ }^{2,3}$ Karen Stegers-Jager, ${ }^{1}$ \\ Jacqueline de Graaf, ${ }^{4,5}$ Cornelia R M G Fluit, ${ }^{5}$ Matthijs de Hoog ${ }^{1,6}$
}

To cite: Gennissen $L$, de la Croix A, Stegers-Jager K, et al. Organic or organised: an interaction analysis to identify how interactional practices influence participation in group decision meetings for residency selection. BMJ Open 2019;9:e026424. doi:10.1136/ bmjopen-2018-026424

- Prepublication history and additional material for this paper are available online. To view these files, please visit the journal online (http://dx.doi org/10.1136/bmjopen-2018026424).

AdIC and KS-J contributed equally.

Received 23 October 2018 Revised 05 September 2019 Accepted 09 September 2019

Check for updates

(C) Author(s) (or their employer(s)) 2019. Re-use permitted under CC BY-NC. No commercial re-use. See rights and permissions. Published by BMJ.

For numbered affiliations see end of article.

Correspondence to

Lokke Gennissen;

L.Gennissen@erasmusmc.nl

\section{ABSTRACT}

Objectives This study aims to shed light on interactional practices in real-life selection decision-making meetings. Adequate residency selection is crucial, yet currently, we have little understanding of how the decision-making process takes place in practice. Since having a wide range of perspectives on candidates is assumed to enhance decision-making, our analytical focus will lie on the possibilities for committee members to participate by contributing their perspective.

Design We analysed interaction in seven recorded real-life selection group decision meetings, with explicit attention to participation.

Setting Selection meetings of four different highly competitive specialties in two Dutch regions.

Participants 54 participants discussed 68 candidates. Methods To unravel interactional practices, group discussions were analysed using a hybrid data-driven, iterative analytical approach. We paid explicit attention to phenomena which have effects on participation. Word counts and an inductive qualitative analysis were used to identify existing variations in the current practices.

Results We found a wide variety of practices. We highlight two distinct interactional patterns, which are illustrative of a spectrum of turn-taking practices, interactional norms and conventions in the meetings. Typical for the first pattern-'organised'-is a chairperson who is in control of the topic and turn-taking process, silences between turns and a slow topic development. The second pattern'organic' — can be recognised by overlapping speech, clearly voiced disagreements and negotiation about the organisation of the discussion. Both interactional patterns influence the availability of information, as they create different types of thresholds for participation.

Conclusions By deconstructing group decision-making meetings concerning resident selection, we show how structure, interactional norms and conventions affect participation. We identified a spectrum ranging from organic to organised. Both ends have different effects on possibilities for committee members to participate. Awareness of this spectrum might help groups to optimise decision processes by enriching the range of perspectives shared.

\section{Strengths and limitations of this study}

- This study is one of the few that investigates the process of decision-making in the complex and high-stakes selection of medical residents.

- Our study adds a new dimension to the discussion about optimising selection practices by focusing on how decision-making practices take place in current practice.

- The data-driven and iterative analytical approach on rich and authentic data helped us identify the variety of different practices, and to zoom in on effects they might have on participation.

- Inherent to all observing interactions, we might have influenced the interactional practices by observing them.

- By purposively selecting seven high-competitive intramural selection decision-making meetings, we might have missed certain interactional patterns more common in less competitive specialties or in extramural specialties.

\section{INTRODUCTION}

Why study medical residency selection meetings?

Adequate resident selection is an important factor in the process of building and retaining a high-quality and diverse medical workforce. ${ }^{1}$ Selecting candidates for residency training programme is a complicated, costly and time-consuming task. ${ }^{2-4}$ Out of a large number of eligible candidates, a selection committee needs to select the future medical workforce. The stakes for candidates applying for a residency position are high and the decisions could be life changing. ${ }^{5}$ Therefore, it is crucial to pursue an optimal and fair selection process. To that end, insights in how the selection process takes place are important. Existing studies have examined the selection of medical professionals using a psychometric 
approach, ${ }^{7-12}$ in which selection is perceived as a step-bystep process uncovering characteristics of the candidates, which would enable an optimal decision. ${ }^{13}$ These studies focus on who should get selected, and how the selected candidates perform when hired. However, in practice, most selection processes are concluded in a selection committee meeting. This context is not taken into account in the most studies. Research has shown that group decisions are often superior to individual decisions, because they are a synthesis of multiple viewpoints and opinions. ${ }^{14}$ In order to reach an optimal decision about the selection of a candidate, all viewpoints and opinions should be available to all the participants in the group discussion. ${ }^{15}$ Unfortunately, decisions are known to be made on the basis of incomplete information about a candidate. ${ }^{16} 17$ Additionally, group decisions are often influenced by procedural, social psychological and economic mechanisms, which does not always contribute to a fair decision-making process. ${ }^{18}$ For example 'evaluation apprehension' could occur, meaning that participants are aware of others judging their input. In the context of group discussions, this may result in participants not sharing information to avoid unfavourable criticism from others. ${ }^{19}$ These kind of effects might be magnified in groups with members from varying hierarchical positions in the organisation, ${ }^{20}$ which is often the case when selecting medical residents. There is little understanding of how the information collected during selection is deliberated and interactively used in committee meetings to get to a joint decision. Since these meetings are the decisive step in the process, knowledge about interaction is crucial to improve selection procedures.

\section{Focusing on interaction}

To fully grasp how selection decisions are reached, we need an understanding of what happens in meetings by examining their interactional practices, which shape interactional patterns. Work examining the interactional processes during selection meetings is scarce. ${ }^{13} 21$ Silverman and Jones studied the selection of administrative officers and showed that decisions about selection were made quite soon after meeting a candidate and that the group decision-making meetings seemed aimed at confirming and justifying the rationality of those decisions. ${ }^{21}$ Bolander and Sandberg studied the actual decision-making process of a selection procedure. ${ }^{13}$ They revealed that selection decision-making is characterised by four inter-related discursive processes: (1) assembling versions of the candidates; (2) establishing the versions of the candidates as factual; (3) reaching selection decisions and (4) using selection tools as sense making devices.

The part of the decision-making process as defined by Bolander and Sandberg that is particularly interesting for this study is 'assembling versions of the candidates'. ${ }^{13}$ One could say that during the group decision-making process an image of a candidate is pieced together by the input from the different participants that can be compared with the desired profile. During the group discussion, each individual committee member brings pieces of the puzzle to the table, based on his or her individual image of the candidate. Together the committee assembles a collective image of the candidate. The challenge is to obtain a coherent view of the candidate on which a decision can be based, while taking into account all relevant information. The risk is that odd, but relevant and possibly valuable pieces of information get lost in the process.

In the present study, we aim to deepen the understanding of the decision-making process of medical resident selection by analysing the interactions that take place during the group discussion. This will result in a better understanding of the current way in which selection decisions are made in practice.

\section{METHODS \\ Data collection \\ Context}

This study was conducted in the Netherlands, where postgraduate training is only accessible via selection procedures. There is no national framework for residency selection, resulting in a great diversity in procedures, since the design of selection procedures is managed by medical associations per specialty or by regional residency programme groups. Although all specialties create their own selection procedures, the most common way of selecting is a traditional job interview setting followed by a decision-making meeting. Predominantly, this involves a first selection on the basis of application letters and résumés, followed by job interviews with the selected candidates. Next, the selection committee discusses the candidates and decides on granting the training positions.

\section{Sampling}

In this study, we started with a convenience sample that turned into a purposive sampling in order to include a wide variety of selection committees practices. We used the network of the programme director research members $(\mathrm{MdH}$ and $\mathrm{JdG}$ ) to identify potential groups that could grant us access to their meetings. Within the available specialties in their network, we searched for a maximum variety. Four different specialties were involved, a surgical specialty, a technical oriented (non-surgical) specialty and two medical specialties. Three of these specialties (the surgical, the technical non-surgical and one of the medical specialties) were sampled within one hospital. Two medical specialties were included in the second hospital. The specialties are all popular specialties, so they have far more applicants than training positions available. Given the richness and the complexity of the data, we stopped sampling after seven observations. All the included selection procedures made use of a traditional job interview process. One selection procedure also included assessments to decide who to invite for the job interviews.

\section{Data}

Data collection took place in two Dutch regions in 2015, of which no further details can be provided in order to 
warrant the anonymity of our participants. Data consist of observations and recordings (audio and video) of seven group discussion meetings in four different specialties (see table 1). The recordings vary from approximately 42 min to over 2 hours. The number of candidates discussed varied from 6 to 17. For transcribing the recordings, we used a method inspired by conventions from conversation analysis (CA) ${ }^{22} 23$ yet since our focus was on participation our transcription system was greatly simplified for legibility. For details on the transcription system, see transcription notation (table 2 ). Table 1 shows a summary of our quantification of the data and the composition of the groups. Each selection committee had a central programme director and at least one resident included. In most cases, the other participants were regional programme directors. With the aim to gain trust of the participants and to get full depth and scope, one researcher (LG) informed the participants and observed all the discussions. Prior to participation, selection committee members were informed by LG about this study. The main reason for the additional observations (non-participant observation)

\begin{tabular}{ll}
\hline Table 2 & Transcription notation \\
\hline$=$ & No break (silence) between turns \\
{[} & Simultaneous speaking \\
$()$. & Short silence less than $0.2 \mathrm{~s}$ \\
$(0.8)$ & Silence (in seconds) \\
$(0)$ & Non-verbal behaviour or specific \\
& vocalisations \\
$?$ & Upwards intonation in the sentence \\
Word & Extra stressed word \\
wor- & Unfinished word \\
{$[?]$} & Inaudible \\
[END FRAGMENT] & Disregarded further interactions \\
\hline
\end{tabular}

We tried to stay true to transcription conventions from $\mathrm{CA},{ }^{22} 23$ yet aimed to present fragments that are legible for medical educators, who are not used to very detailed transcripts. As our focus was on floor distribution and conversational turns, we simplified our transcription system accordingly. was to be able to cover possible blind spots of the camera. For the recordings, as well as the observations, we aimed for a setup that minimised possible disturbance.

Patient and public involvement

No patient involved.

\section{Analytical framework}

Analytical approach

Our ontological position is that meetings are generative and constitutive activities. We recognised the decisionmaking process in these meetings as a dynamic and emergent social process, in which the eventual decision is negotiated through the conversational actions of multiple participants. This negotiation takes place on the conversational floor, ${ }^{24}$ which describes the medium on which this negotiation takes place. In order to participate in the negotiation, one needs to be able to take the floor to bring their input (perspective/information/opinion) to the table. So, we define participation as the degree to which attendees make active contributions, such as sharing information and expressing unique viewpoints. Since our meta-theoretical goal is to understand how these specific meetings can be facilitated to enhance equality of participation, our special focus is on the opportunities for all committee members to participate. By conceptualising the decision-making as a negotiation, it inherently becomes relevant what the composition of meeting attendees is, and how the power and influence is divided in this negotiation.

In interaction, there are implicit rules and assumptions that are followed and made. Dependent on conversational norms and conventions, interactional patterns that hinder or stimulate participation might differ. In some cases, silence might stimulate participation, yet in other cases, turns might be allocated by the chair person and silence will not play a role in stimulating participation. At the same time, phenomena such as interruptions, monologues and ending the discussion early, might or might not be hindering depending on prevailing norms and conventions. Since these interactional phenomena should always be seen in the context of prevailing norms and conventions, an interactional focus on participation was taken. 
Table 3 The four inter-related discursive processes in group decision-making concerning personnel selection identified by Bolander and Sandberg

\begin{tabular}{|c|c|}
\hline Phase 1 & Assembling versions of the candidates \\
\hline Phase 2 & $\begin{array}{l}\text { Establishing the versions of the candidate } \\
\text { as factual }\end{array}$ \\
\hline Phase 3 & Reaching selection decisions \\
\hline Phase 4 & $\begin{array}{l}\text { Using selection tools as sense making } \\
\text { devices }\end{array}$ \\
\hline
\end{tabular}

We used a hybrid approach to study participation in the interactions, combining word counts with an inductive qualitative approach. With interaction as our main focus, we drew on previous work and concepts from CA. ${ }^{25}$ Our attention will be aimed at phases 1 and 3 (table 3 ) in the meetings, as the level of participation in these phases could have considerable impact on the outcome of the decision. ${ }^{13}$ Analysis was an iterative process, in which we examined interactional phenomena of each group discussion, compared the patterns found in different group discussions, and actively searched for divergent cases. ${ }^{26}$

This study is part of a larger project researching selection procedures, containing background data such as rankings of candidates. Individual committee members ranked all candidates at three moments: (1) after they received the motivation letter and résumés, prior to the job interviews; (2) after the job interviews, prior to the group discussion; (3) and after the group discussion. Although our primary focus was on the interactional aspects, we enriched and triangulated our analyses by including contextual knowledge, such as rankings and the nature of the selection procedures. This allowed us to have a more holistic view on the process, while keeping the interactional analysis as the basis of our work. This aligns with our perspective on language and context, which we conceptualise as Halliday and Hasan stated: 'The notions of text and context are inseparable: text is language operative in a context of situation and contexts are ultimately construed by the range of texts produced within a community. ${ }^{27}$

This study included multiple sources of data, managed by different software programs including Atlas.ti, Transana and Excel. Atlas.ti was used for management of the full qualitative data. Excel was used for word count purposes and the rankings. Transana was used to zoom in the interactional phenomena.

\section{Interactional phenomena}

We concentrated particularly on the conversational floor, ${ }^{24}$ and the implicit norms and conventions in decision-making meetings that encourage or discourage participants to participate in the discussion. So, we were interested in the occupancy of the conversational floor: who speaks? who decides who is allowed to speak? can anyone speak at any time? Important interactional phenomena that we focused on in the analysis are: turn-taking, silences and interruptions. In addition, we concentrated on the norms

\section{Box 1 Interactional phenomena}

Turn-taking, length of turns, silences and interruptions Turn-taking is the process of taking or giving (allocating) the floor to a new speaker. Sacks et al distinguish two groups of turn allocation practices: (1) turn allocation, a mechanism in which the current speaker selects the next speaker and (2) self-selection, a mechanism in which the next speaker selects himself for the next turn. ${ }^{34}$ In the analysis, attention is given to the length of turns and the way a turn ends: by being interrupted, by allocating a next speaker, by silence.

In naturally occurring talk in Western cultures, participants in a conversation will aim for a minimal amount of silences and a continuity of talk. ${ }^{35}$ At the same time, silences occur when no speaker has been allocated, when no speaker self-selects, or when an allocated speaker refuses to take the turn. Sometimes, there is interruption or multiple participants speaking at the same time, which can be positive as it signals a feeling of 'togetherness' ${ }^{36}$ or can be a threat to an equal group discussion when it means certain participants are barred from sharing their contribution.

\section{Norms and conventions}

Institutional meetings differ from ordinary conversations in the sense that they are planned in advance, have a prespecified purpose, are time bound, have a set agenda and most often have appointed responsibilities. $^{37}$ This implicates that there are tasks and responsibilities within the meeting that give participants obligations, as well as rights in the conversation. By looking at tasks, responsibilities, obligations and rights which become apparent by interactional practices, we will zoom in to the specific norm and conventions in group decision meetings.

and conventions, which are common in this context. For a more detailed description of the interactional phenomena that had our focus, see box 1 .

All participants were informed about the purpose of the study. Prior to the group discussion, written informed consent was obtained. All participants agreed with recording the group discussion. Names of committee members and candidates were replaced by a code. All files were stored on an encrypted hard-drive.

\section{Reflexivity}

In our study, the research process is one of active engagement, where researchers bring their own backgrounds and assumptions to the analytic process. ${ }^{29}$ It is important to reflect on how our backgrounds might influence our approach. The lead author LG is a female medical doctor, who has worked 1 year as resident-not-in-training, after which she started her $\mathrm{PhD}$ in medical education. After finishing her PhD, she wants to start her postgraduate medical training. Two of the research team members, $\mathrm{MdH}$ and JdG, are programme directors with a lot of experience in selecting residents for postgraduate medical education. Their network was used for sampling. The other members of the research team (KS-J, AdlC and CRMGF) have significant experience in researching medical education, but are not working as medical doctor. KS-J is an educational researcher with expertise in selection and diversity in medical school. CRMGF is a medical doctor and educationalist and works as postdoctoral educational researcher with expertise in workplace learning. AdlC has a background in education 
Table 4 Spectrum ranging from organic to organised

\begin{tabular}{ll}
\hline Organic & Organised \\
\hline Short turns & Long turns \\
\hline Lots of interruptions & Few interruptions \\
Self-selection & Allocated turns \\
Few silences between turns & Silences between turns \\
Disagreement voiced & Disagreement is not voiced \\
Topic transitions smooth & Topic transitions by chair \\
Topic can be changed by & Topic change by chair \\
everyone & \\
\hline
\end{tabular}

and linguistics and works as a teacher and researcher (using discourse and CA) in higher and medical education.

To avoid influencing the process of decision-making, the data gathering and analysis was done by two researchers (LG and AdlC), who had no direct role or connection with the residency-selection decision-making, therefore, having an outsider role. LG had interviewed most of the selection committee members prior to observing them in the group discussion.

During the gathering and analysis of the data, an interdisciplinary team (MdH, JdG, KS-J and LG) discussed the results and the process on a regularly basis. During these discussions, the different backgrounds were explicitated and used for the interpretation. Through these discussions, the primary researchers kept a critical and open view on the data and results. Additionally, a data session was held with the medical education research group in Rotterdam, in which researchers with different backgrounds were invited to share their observations and ideas about parts of the transcribed data. LG built an audit trail by documenting the analytical decisions and meetings.

In the online supplementary file 1 the Consolidated criteria for REporting Qualitative research (COREQ) checklist for this particular study can be found. Where the COREQ mentions 'interview', we replaced it by 'observation'. 30

\section{RESULTS}

The interactional patterns in the group discussions data were extremely varied, as was the occupancy of and access to the conversational floor. The occupancy of the floor, when quantified by word counts, varied greatly between participants and between groups. On one extreme, the most speaking participant in the group accounted for $54 \%$ of all spoken words, and the least speaking participant spoke $1 \%$ of all words in the meeting. The least widely dispersed group showed a range between $10 \%$ (of words spoken by the least speaking participant) and 30\% (of words by most speaking participant). Table 1 shows a summary of the quantified interactional phenomena. In order to present our findings in a concise yet clear way, we will present a description of two meetings that were illustrative of two very different interactional patterns, conversational norms and conventions. Both discussions are focused on a candidate with differences in ranking position between attendees, which suggests different viewpoints. Two phases are described, phase 1, the part of the discussion in which the versions of the candidates are assembled, and phase 3 in which the actual decision is made (see table 3 ).

Typical for the first pattern-'organised'-is a chairperson who is in control of the topic and the turn-taking process. Other characteristics are longer turns, few interruptions, allocated turns or space for self-selection by silences between turns, disagreement is not voiced and a slow topic development.

The second pattern-'organic'—can be recognised by short turns, overlapping speech, interruptions, selfselection, few or short silences between turns, clearly voiced disagreements and negotiation about the organisation of the discussion. The characteristics of these patterns are presented in table 4.

We will continue to elaborate these two sides of the interactiona 1 spectrum, first 'organised', then 'organic'. In tables 5-8, illustrative examples of the interactional phenomena are shown. For more extensive fragments, see online supplementary appendix. The names used in the fragments are pseudonyms.

\section{ORGANISED}

\section{Phase 1}

Turn-taking, silences and interruptions

In this pattern, in general, turn-taking seems to be quite neatly organised with only one person occupying the floor at any given time. The turns are 30 words per turn on average. Interruptions occur when participants have shared knowledge of a candidate and want to complete the description of a candidate. ${ }^{31}$ The chair often explicitly allocates the next speaker or invites the group to take the floor by making an open invitation. Self-selection is seen in this interactional design, but only when it is very clear the floor is open to take.

Table 5 Examples of interactional phenomena phase 1 organised

\begin{tabular}{|c|c|}
\hline \multirow[t]{2}{*}{ Example of turn-allocations } & Line 485: Alex: who's first? \\
\hline & Line 495: Alex: Jade? \\
\hline $\begin{array}{l}\text { Example of self-selection after } \\
\text { silence }\end{array}$ & $\begin{array}{l}\text { Line 497: (1.9) } \\
\text { Line 498: lan: At first when she entered we thought for a minute hey she looks a little mousy } \\
\text { but when the interview got going that went well it completely went away [really }\end{array}$ \\
\hline
\end{tabular}

Example for asking for specific

Line 506: Lynn:=would want so that was fun so [erm

content

Line 507: Alex:

[fits in? 
Table 6 Examples of interactional phenomena phase 3 organised pauses to create opportunity to react
Part of the long turn with

Line 1113: Alex: [after this elaborate explanation on to (1.4) the ranking (5.2) for which we'll have the same discussion as for the clinical profile that we'll have to decide where to draw the line for the discussion and then like we do every year more or less from top to bottom and finally agree upon an erm (0.4) allocation erm for which we have four positions to allocate erm I suggest we exclude everyone without at least an A erm from the discussion about the places for it's not realistic that you would climb so much that you would end up in there so anyone still wishing to go to bat for Diana Fiona or Lucy that we should include them into the discussion anyway (2.0)

Part of the proposal and
question
Line 1113: Alex: for which (0.4) erm (2.9) we if I look at the discuss- correct me if I'm wrong if I look at the discussion there appears to be a lot of support for Holly from everybody really so both in the A's but also if you if you (0.7) erm listen to the reasoning behind the $A$ there is broad support for Holly as a training candidate and I think we can tick this one off right away that this one is in unless anyone (0.8) erm objects

The reinforcement on Line 116: Dion: red tick red tick

decision

\section{Norms and conventions}

The conversational tasks and responsibilities to guide this group process seem to lie on the shoulders of the chairperson. In this role, the chairperson is conversationally in control. The control is performed by allocating the turns, but also by starting the discussion about the candidate and ending the topic. The chairperson decides when enough is said about this candidate to be able to go on to the next. Lastly, he can also ask for particular input by asking about specific content. The chair allocates the floor to multiple committee members to express their opinions. Most often only one person speaks, and the others listen or are quiet. In the discussion regarding the candidate, the committee members rarely react to each other's opinions directly. The chair plays an important part in the turn-taking dynamic and seems to take on responsibility of creating one coherent, sufficient image of the candidate.

\section{Phase 3}

\section{Turn-taking, silences and interruptions}

In the design of the actual decision-making again the control of the chair is seen. In a longer-than-average turn (244 words original transcript; average of 30), the chair interpretatively summarises what the previous discussion has produced. By pausing after different statements, he gives the committee members the opportunity to react on these statements. When nobody reacts he continues, ending with a proposal for a decision. After his proposal, the chair leaves an invitation for people who might disagree, followed by a silence of three seconds. None of the committee members takes the floor to object. Another selection committee member, Dion, who takes the floor, yet instead of objecting, he reinforces the proposal.

\section{Norms and conventions}

Where in the previous phase the chairperson, Alex, seemed to have the responsibility to collect information from the selection committee members, here his tasks and responsibilities are oriented towards making a decision. He does this on his own, without asking for new information or additional input from the committee members. At the end, rather than inviting any contributions, Alex specifically asks for objections to the decision he has proposed. Dion takes the floor, yet rather than objecting, he expresses agreement to the proposed decision. This means that the floor might be open to objections, but Alex-with the support of Dion-communicates that objections are very unlikely.

\section{Table 7 Examples of interactional phenomena phase 1 organic}

\section{Examples of self-selection Line 57: Clark: I did}

Line 58: Emma: yes but I thought he responded rather nicely to th- I did think so based on his CV I really thought so but I thought he dealt with that [rather nicely

Examples of interruption Line 47: Fay: yes I had wr[itte[n that down too yes
Line 48: Adam:
Line 49: Clark: [by [far
Line 61: Brent: I thought he was one of the two best
candiates I [saw today
Line 62: Emma: [I thought so too actually
Line 63: Clark:
[Oh no, I didn't

Example of topic transition Line 151: Adam: I'm afraid that might be asking [for trouble

by committee member Line 152: Brent:

[l thought the same thing about Claire [gets [an absolute contraindication from me 
Table 8 Examples of interactional phenomena phase 3 organic

Examples of moving towards topic closure

Line 1210: Adam: okay are we

agreed on this?

Line1211: (0.3)

Line 1486: Brent: yes that's how we'll do it right? yes

Line 1487: (2.0)

Example of reinitiating Line 1212: Clark: I would like to see
the discussion after
topic closure move

\section{ORGANIC}

\section{Phase 1}

\section{Turn-taking, silences and interruptions}

The turns in this group discussion are shorter than the turns in the organised one. The average turn has 12 words, with a range of 9-16 words. The floor is often occupied, there are few silences, and the turn-taking procedure is less clearly structured than in the organised group discussion. Turns are not allocated by the chair, but often the next speakers self-select. Committee members do not always wait for the floor to be open, but take the floor by interrupting the previous speaker. Committee members can be talking at the same time in order to add their viewpoint, or can talk over one another to express agreement.

\section{Norms and conventions}

The conversational tasks and responsibilities seem to be shared among the different committee members. Committee members all join the discussion and are all expressing their own personal viewpoints. Although the chairperson starts by setting the topic, other selection committee members can transition the conversation to a new topic. The chairperson starts the discussion by stating his opinion, in two short sentences, without any argumentation backing up this opinion. He is immediately challenged by a selection committee member, leading to a disagreement in versions of the candidate. While the floor is rarely open to take and is not once explicitly allocated to a committee member, participants seem to have their own task in bringing their puzzle piece to the table. Sometimes acquiring or maintaining the floor requires conversational mechanisms and techniques, like voiceraising or keep on talking while being interrupted.

The chairperson tries to-unsuccessfully-move the discussion toward a decision as but the committee continues to deliberate. At a later stage, the transition to a new topic is successfully made by one of the committee members.

In this fragment, the committee members do not agree on attributes of the candidate. This group does not seem to search for one overarching image of the candidate on which there is agreement. They do challenge each other's visions and ideas, yet allow the different-seemingly conflicting-perceptions to coexist.

\section{Phase 3}

Turn-taking, silences and interruptions

Turn-taking in this fragment is dynamic, involving many participants with brief turns. The decision-making phase in the organic one is longer and less result driven compared with the organised one: in the second part of this phase, different options are explored and the floor is open for suggestions other than reject or accept. Compared with phase 1 of this group, phase 3 has more silences.

\section{Norms and conventions}

The task and responsibility for reaching a decision seems to be taken on by all committee members. The discussion of the decision regarding this candidate is reinitiated by a question of Fay, asking whether Brent agrees with the decision. The group thereafter elaborates and explores different options. When the chairperson is seemingly satisfied with the discussion regarding the decision, he steers the discussion to an end with a question. Clark, however, restarts the discussion. Further elaboration is allowed until Brent tries to lead the discussion to an end by saying: 'yes that's how we'll do it right? yes' (line 1486). Now the group seems to agree the discussion has come to an end by moving along towards an end and Adam definitely ends the discussion with his word: 'Done'. (line 1497).

\section{DISCUSSION}

\section{Organic and organised: a spectrum}

This study explored which interactional practices were stimulating or hindering participation in group discussion meetings concerning residency selection. Using a hybrid analytic approach, we were able to examine the distribution of the floor by looking at turn-taking, interruptions, silences between turns as well as norms and conventions. Word counts showed great variation in participation between committee members, with ranges between $1 \%-54 \%$ and $10 \%-30 \%$. Our interactional analysis showed a variety of practices that affect participation. The findings of this study echo the ideas put forward by Edelsky in her work on gender and interaction in 1981 - Organic resembling her Floor 2, and Organized resembling her Floor $1 .{ }^{24}$ Our results illustrate a spectrum that ranges from organic to organised practices (see table 4). Typical for the-'organised'-meeting is that the chairperson is in control of the topic and the turn-taking process, and there are silences between turns and a slow topic development. The second pattern-'organic'_can be recognised by overlapping speech, clearly voiced disagreements and negotiation about the organisation of the discussion. Both interactional patterns have an influence on the availability of information, as they create different types of thresholds for participation. To clarify what happens with regard to the threshold of participation, we will-again-use a metaphor. If we compare the conversational floor to a musical stage, the 
organised structure would entail that one person walks onto the floor, does a dance routine and leaves the dance floor again. The chair is the gatekeeper: he points at the next person to dance, or waits until a new person steps onto the dance floor for a routine. The organic style is a busier stage: participants can step on the stage even when there is already someone dancing, people are not invited to dance, but step onto the floor themselves. The way the chair occupies the floor, is similar to the way other participants do. One might experience a hesitation before joining the organised stage, as everyone is watching while you perform your dance routine and might form opinions about the routine. Hesitations before joining the organic stage can also be present, as you have to be quick to join the stage or you might miss your chance: dance moves are quick and the floor is always taken.

Taking the (stage) floor implies taking a risk of losing 'face' in front of the group. As in this expression, face is a central term in the politeness theory, ${ }^{32}$ in which face is defined as the public self-image that one will try to protect. This principle complicates taking the floor, especially with deviant viewpoints. It becomes even more complex when there are power differences between interactional partners, since politeness strategies (to protect face) rely on power differences as well. This is probably true in the context of selecting for medical residencies; hierarchical power differences exist and therefore competing interests could influence the discussion as well as the decisionmaking. This principle of 'face' and different competing interests between committee members could hinder an open discussion. The floor might be technically open for everybody, but other undercurrents might raise thresholds for giving your viewpoint or opinion.

Translating it back to the group discussion meetings, we notice potential advantages and disadvantages of each style. The organised style gives room for participants to have floor time without being interrupted, is probably more time-efficient, and it is clear who is finally in charge: the chair. The downsides are that speakers might experience pressure to 'perform' in a speech turn, and that they might feel they have to meet certain expectations, for example, those of the chair or those of earlier speakers (eg, that their puzzle piece has to fit with the other puzzle pieces). This pressure might mean that not all participants dare to take the floor, or do not dare to speak their minds freely. There is a risk for an uneven distribution of the floor, which may result in missing relevant information and viewpoints. The organic practice might also have unequal distributions of the floor, because to take the floor, participants have to be quick and persistent in their attempts. It is less time-efficient because decisionmaking seems to be more group based, in which the chair is part of the group. Although the chair's input could still be valued as more important, because of his hierarchical position. This style might create a safer atmosphere in which participants can disagree with one another, as there seems to be acceptance of multiple viewpoints. But by letting the different puzzle pieces coexist, it might be harder to decide whether the mutual puzzle of the candidate matches with their desired new resident. These descriptions of the extremes are insightful and a starting point for constructing committee meetings that contain the best of both worlds.

\section{Implications for research and practice}

Researching selection decision-making

Our results suggest that structure in meetings has an impact on the interactional dynamics, which in turn impacts possibilities for sharing information between participants. This is of great importance when considering diversity in our medical workforce: for diversity in candidates, diversity in opinions should be welcomed in selection meetings. A different perspective, which might be left unshared because it is different-and the threshold to share it is high-might be crucial in the perspective of diversity. Moreover, if we wish to benefit from diversity in our medical workforce, a feeling that these different perspectives are valued and are allowed to be shared, is of key importance.

An area for further research could be to explore in more detail what the effects are of micro politics (different interests and power relations) in these specific meetings on participation (floor taking) as well as on information sharing (withholding or distorting relevant information). Besides participation and information sharing, future work might also aim its scope on the way opinions are phrased and on the ways in which committee members present the candidates and create an image of them.

\section{Implications for practice}

When we fed back our results to research participants, we noticed that talking about these findings led to constructive and useful discussions about the way they want to organise their committee meetings, group discussions and interactional practices. Awareness of the spectrum and discussing the importance groups assign to participation seem to already have practical impact. Although our results do not direct towards a clear-cut optimal solution, there are some possible implications for selection practices.

\section{Team training}

Awareness of the spectrum of interactional patterns will allow committee members and chairs to consciously construct the desired interactional setting for group discussion. In their search for a desired interactional setting, groups will be stimulated to think about how they want to optimally use the potential of group decision-making.

A promising technique to make participants aware and to evaluate and discuss problems or roadblocks that can occur in interaction is Conversation Analytic Role-play Method (CARM). CARM is a method in which participants discuss real data from an interactional study, similar to this one. ${ }^{33}$ By listening and looking at a discussion rolling out line by line, teams can discuss what they think 
will happen next, and become aware of their implicit preferences and own communicative behaviour.

\section{An independent discussion facilitator}

The team leader is the person who often has the most hierarchical power, which might have its influence on the conversational participation. In the organised structure, the team leader is also conversationally in charge (allocating turns, initiating new topics, proposing the decision). Since the decision-making process in itself is already complex and demanding, as one has to try to listen, think, add, collaborate and build, it might be wise to consider separating the roles of the conversational leader and of the hierarchical leader in the discussion. In the organic structure, an independent discussion facilitator/leader might be particularly helpful in ensuring everybody gets a chance to bring their puzzle piece to the table. In both cases, one might not remove the power influences, since these can be exercised through talk and the ways in which that talk flows. Nevertheless, an independent conversational leader, whose only task is to control the floor, to divide speaking turns equally and to actively challenge the group to share multiple versions of candidates might be an easy to accomplish intervention to enhance participation.

\section{Strengths and limitations}

Group decision-making concerning residency selection is complex and although our understanding is growing, a full understanding of this process is lacking. This hampers optimising selection. Our results show the need for researching selection decision-making in a context-sensitive way in actual practice as a first step towards more diversity. We contributed by showing that interactional patterns can have an influence on the information availability by creating thresholds for participation. By using actual practices in this research, we were able to take the context into account.

A limitation of this study, inherent to observing interactions, is that we might have influenced the interactional practices by observing them. We strived to keep this influence to a minimum in our study setup, yet are unable to rule out differences between 'natural' behaviour and our observed behaviour. We do think this effect will be small and will have faded away quickly after the beginning of the group discussion. A second limitation is that by wide variety sampling, we also had varying group discussions. This gave us a good sense of the current variety and enabled a wide exploration, but made a more detailed focus on shared patterns more complex.

\section{CONCLUSION}

We identified a spectrum of possible ways to structure residency selection group decision-making meetings, ranging from organic to organised, and identified which effects these structures could have on the participation of selection committee members. Although our data showed a wide variety of possibilities and our results did not offer one clear cut most effective solution, these insights allow groups to consciously structure their group decisionmaking in order to benefit from more opinions and viewpoints in the decision-making. Group decision-making will benefit from further empirical work to unravel the practical implications for this complicated process.

\section{Author affiliations}

${ }^{1}$ Institute of Medical Education Research Rotterdam, Erasmus MC, Rotterdam, The Netherlands

'LEARN! \& LEARN! Academy, Vrije Universiteit Amsterdam, Amsterdam, The Netherlands

${ }^{3}$ Research in Education, Amsterdam UMC, VUmc School of Medical Science, VU Medical Center, School of Medical Sciences, Amsterdam, The Netherlands ${ }^{4}$ Department of Internal Medicine, Radboud University Medical Center, Nijmegen, The Netherlands

${ }^{5}$ Radboudumc Health Academy, Radboud University Medical Center, Nijmegen, The Netherlands

${ }^{6}$ Pediatrics/Pediatric Intensive Care Unit, Erasmus MC - Sophia Childrens Hospital, Rotterdam, The Netherlands

Acknowledgements We are very grateful to all of the selection committee members for their cooperation in our research. We would like to thank Marloes Duitsman for her help in the beginning of data analysis. We would like to thank Peter de Hoog for editorial assistance.

Contributors $\mathrm{LG}$ is a female medical doctor by training and is a $\mathrm{PhD}$ student in medical education, focusing on recruitment and selection for a future diverse and adequate workforce, with a Dutch background. Her interest in the topic originated from her own career experiences while studying medicine and a longstanding interest in education. KS-J is a female educational scientist and works as an associate professor at the institute of Medical Education Research Rotterdam. Her research focuses on diversity in the selection for medical education. AdIC is a female linguist. She works as a teacher and researcher (using Conversation Analysis) in higher and medical education. CRMGF is a female medical doctor currently working as associate professor and educational researcher with expertise in feedback in workplace learning. JdG is a female programme director and professor at the internal medicine department. $\mathrm{MdH}$ is a male programme director and professor at the pediatric department. LG, AdIC, KS-J, CRMGF, JdG and MdH contributed to the design of the study and interpretation of the data. LG observed and recorded the group discussions. $L G$ and AdIC were responsible for the main data analysis. LG, AdIC, KS-J, CRMGF, JdG and MdH contributed to and approved the final manuscript.

Funding This work was supported by the Dutch Ministry of Health, Welfare and Sports; Project Dedicated Schakeljaar.

Competing interests None declared.

Patient consent for publication Not required.

Ethics approval This study has been approved by the Dutch Association for Medical Education Ethical Review Board (NVMO-ERB), dossier number 421. Selection committee members gave informed consent for sharing of anonymised data.

Provenance and peer review Not commissioned; externally peer reviewed.

Data availability statement Additional anonymized data available from the main author upon request.

Open access This is an open access article distributed in accordance with the Creative Commons Attribution Non Commercial (CC BY-NC 4.0) license, which permits others to distribute, remix, adapt, build upon this work non-commercially, and license their derivative works on different terms, provided the original work is properly cited, appropriate credit is given, any changes made indicated, and the use is non-commercial. See: http://creativecommons.org/licenses/by-nc/4.0/.

\section{REFERENCES}

1 Makdisi G, Takeuchi T, Rodriguez J, et al. How we select our residents--a survey of selection criteria in general surgery residents. J Surg Educ 2011;68:67-72. 
2 Strand EA, Moore E, Laube DW. Can a structured, behavior-based interview predict future resident success? Am J Obstet Gynecol 2011;204:e13:446. e1-446.e13.

3 Gordon MJ, Lincoln JA. Selecting a few residents from many applicants: a new way to be fair and efficient. J Med Educ 1976;51:454-60.

4 Brothers TE, Wetherholt S. Importance of the faculty interview during the resident application process. J Surg Educ 2007;64:378-85.

5 Green M, Jones P, Thomas JX. Selection criteria for residency: results of a national program directors survey. Acad Med 2009;84:362-7.

6 Campagna-Vaillancourt M, Manoukian J, Razack S, et al. Acceptability and reliability of multiple mini interviews for admission to otolaryngology residency. Laryngoscope 2014;124:91-6.

7 Patterson F, Knight A, Dowell J, et al. How effective are selection methods in medical education? A systematic review. Med Educ 2016;50:36-60.

8 Roberts C, Khanna P, Rigby L, et al. Utility of selection methods for specialist medical training: a BEME (best evidence medical education) systematic review: BEME guide No. 45. Med Teach 2018;40:3-19.

9 Schmitt N, Sinha R. Validation support for selection procedures. In: APA handbook of industrial and organizational psychology, 2011.

10 Schmidt FL, Hunter JE. The validity and utility of selection methods in personnel psychology: practical and theoretical implications of 85 years of research findings. Psychol Bull 1998;124:262-74.

11 Sackett PR, Lievens F. Personnel selection. Annu Rev Psychol 2008;59:419-50.

12 Hausknecht JP, Day DV, Thomas SC. Applicant reactions to selection procedures: an updated model and meta-analysis. Pers Psychol 2004;57:639-83.

13 Bolander P, Sandberg J. How employee selection decisions are made in practice. Organ Stud 2013;34:285-311.

14 Kerr NL, Tindale RS. Group performance and decision making. Annu Rev Psychol 2004;55:623-55.

15 Sessa VI, Taylor JJ. Choosing leaders: More cooks make a better broth. Consult Psychol J Pract Res 2000;52:218-25.

16 Wittenbaum GM, Park ES. The collective preference for shared information. Curr Dir Psychol Sci 2001;10:70-3.

17 Stasser $\mathrm{G}$. The uncertain role of unshared information in collective choice. Shared cognition in organizations: The management of knowledge, 1999: 49-69.

18 Wang S, Noe RA. Knowledge sharing: a review and directions for future research. Hum Resource Manag Rev 2010;20:115-31.
19 Bordia P, Irmer BE, Abusah D. Differences in sharing knowledge interpersonally and via databases: the role of evaluation apprehension and perceived benefits. European Journal of Work and Organizational Psychology 2006;15:262-80.

20 Wolfe E, Milliken F. Organizational silence: a barrier to change and development in a Pluralistic world. Acad Manage Rev 2000;25:706-25.

21 Silverman D, Jones J. Organizational work: the language of grading, the grading of language. Collier Macmillan, 1976.

22 Psathas G, Anderson T. The 'practices' of transcription in conversation analysis. Semiotica 1990;78:75-100.

23 Jefferson G. Glossary of transcript symbols with an introduction. Pragmatics and Beyond New Series, 2004: 125. 13-34.

24 Edelsky C. Who's got the floor? Lang. Soc. 1981;10:383-421.

25 Sidnell J. Conversation analysis: an introduction. John Wiley \& Sons, 2011.

26 Silverman D. Doing qualitative research: a practical Handbook. SAGE Publications Limited, 2013.

27 Halliday MA, Hasan R. Language, context, and text: aspects of language in a social-semiotic perspective; 1989.

28 Jones ROD, Thornborrow J. Floors, talk and the organization of classroom activities. Lang. Soc. 2004;33:399-423.

29 Watling C, Driessen E, van der Vleuten CPM, et al. Music lessons: revealing medicine's learning culture through a comparison with that of music. Med Educ 2013;47:842-50.

30 Tong A, Sainsbury P, Craig J. Consolidated criteria for reporting qualitative research (COREQ): a 32-item checklist for interviews and focus groups. Int J Qual Health Care 2007;19:349-57.

31 Lestary A, Krismanti N, Hermaniar Y. Interruptions and silences in conversations: a Turn-Taking analysis. PAROLE J. Linguist. Edu. 2018;7.

32 Brown P, Levinson SC. Politeness: some universals in language usage 1987;4.

33 Stokoe E. The conversation analytic Role-play method (CARM): a method for training communication skills as an alternative to simulated Role-play. Res Lang Soc Interact 2014;47:255-65.

34 Sacks H, Schegloff EA, Jefferson G. A simplest systematics for the organization of turn taking for conversation. In: Studies in the organization of conversational interaction, 1978: 7-55.

35 Mazeland HJ. Inleiding in de conversatieanalyse. Coutinho, 2003.

36 Carroll D. Psychology of language. Nelson Education, 2007

37 Svennevig J. Interaction in workplace meetings. Discourse Stud 2012;14:3-10. 